\title{
Imagining Lesbian Citizenship: A Kiss \& Tell Affair
}

\author{
B.J. WRAY
}

\begin{abstract}
B.J. Wray is a doctoral candidate in the Department of English at the University of Calgary where she is writing her dissertation, "Imagined Citizenship: Nationalism and Sexuality in English-Canadian Lesbian Texts. " Part of that dissertation, this piece reconsiders the relationship between representations and lesbian rights activism through an examination of the citizenship and community models developed in the performance art of Kiss \& Tell. Responses may be sent to her via email (bjwray@ucalgary.ca).
\end{abstract}

If we proliferate the possibilities on the margin without disrupting the center, then we have unwittingly preserved the distinction between margin and center rather than contributed to a more fatal displacement of heterocentrism. - Judith Butler 1998, 227

I find my marginalization a poor basis for a politic. It feels like my community ends up constantly letting itself be defined by the power centre it is working against. I am more interested in looking for community definitions within our communities. But what would those definitions be? - Lizard Jones, Kiss \& Tell 1994, 54

Given the already overwrought status of millennial musings, I hesitate to begin this article with my own foray into a retrospective assessment of lesbianism at the present time. But I am tempted to wax fondly on the milestones of this past decade of the dyke: the 


\section{6 / Wray}

covers of Newsweek (January 21, 1993) and Vanity Fair (August 1993); the media frenzy surrounding Ellen's coming out; ${ }^{1}$ the sudden mainstream visibility of more lesbian musicians than I could possibly enumerate. And, while we are tallying up the lesbian score sheet, who could forget Claire of the Moon (Nicole Conn, 1992), The Incredibly True Adventures of Two Girls in Love (Maria Maggenti, 1995), When Night Is Falling (Patricia Rozema, 1995), Bound (Andy Wachowski, 1996), Fire (Deepa Mehta, 1996), Love and Other Catastrophes (Emma-Kate Croghan, 1997), All Over Me (Alex Sichel, 1997), The Watermelon Woman (Cheryl Dunye, 1997), High Art (Lisa Cholodenko, 1998), Better Than Chocolate (Anne Wheeler, 1999) ... Luxuriating in these late twentieth-century moments, it appears that the state of the (predominately white, upper-middle-class, skinny and stylin') lesbian nation has never been more prominent, nor more fashionable. Our heady fifteen minutes of fame will undoubtedly be recorded in the annals of various rights organizations as a watershed along the trajectory of lesbian liberation. The liberatory power ascribed to these contemporary representations may be traced to the intimate connection between visibility politics and rights discourses in North America. The first section of this paper takes to task this connection and the normative models of citizenship it (re)produces. The second section examines the alternative paradigms of sexual citizenship offered by Kiss \& Tell, a Vancouver-based performance collective.

Liberationist movements have always sought to flood the cultural mainstream with positive images in the hopes of displacing the pathological legacy of lesbian deviance, perversion, and unnaturalness. As Arlene Stein reminds us, "Lesbian life is indistinguishable from our images of it" (63). Remaining loyal to the power wielded by the visible realm, Pride discourses of all sorts wholeheartedly embrace a representational logic that promotes the political effectiveness of identity counterimages. We are not surprised, then, that the celebrity status of the aforementioned

${ }^{1}$ Both comic Ellen DeGeneres and the title character she played on the $\mathrm{ABC}$ prime time sitcom Ellen publicly came out as lesbians in April, 1997. The character of Ellen Morgan announced her sexuality in a special one-hour episode on April 30, 1997. 
lesbian icons is reinforced by gay and lesbian rights organizations desiring to solidify a queer presence within popular culture and, by extension, within society at large. ${ }^{2}$ The usage of these figures as counterimages is intimately linked to the stereotypes they are meant to oppose.

As the case of Ellen DeGeneres illustrates, the acceptability of a leading lesbian on prime-time television hinges upon the explicit rejection of deviance in favor of an almost hyperbolized normativity. ${ }^{3}$ DeGeneres's sitcom character, Ellen Morgan, an unassuming, white, middle-class girl-next-door who happens to be a lesbian, fulfills enough of the conventional registers of normality to make her palatable to a 'general' audience. Time magazine's cover story on Ellen's coming out embodies this drive to secure her normality. Throughout this piece, Ellen is analogously linked to Mary Richards, the lead character of the 1970s sitcom The Mary Tyler Moore Show and the original girl-next-door: "Like Mary Richards before her, Ellen Morgan functions as her show's center, around whom the rest of the cast revolves - structurally, Ellen Morgan is Mary Richards, except she likes girls" (46). The interchangeability of Ellen Morgan and Mary Richards confirms Ellen's normative status by casting her as the reincarnation of a television icon. Even more importantly, Ellen's lesbianism is depicted both as incidental, and as an addition tacked on to an otherwise familiar and recognizable television personality. Ironically, in an attempt to retain her 'universal' appeal, Ellen's coming out initiates a recloseting of her lesbian desire:

"Ellen won't become the lesbian dating show" is the party line one hears again and again. "Ellen Morgan is still in a very heterosexual situation," insists Dava Savel [one of

${ }^{2}$ The reliance on celebrity status as a means of garnering public support for gays and lesbians is exemplified by the appointment of Chastity Bono (daughter of Sonny and Cher) as the Media Relations Co-Ordinator for America's preeminent gay rights organization, The National Gay and Lesbian Task Force.

${ }^{3}$ Two excellent essays on the relationship between normativity and lesbian visibility in popular culture are Danae Clark's "Commodity Lesbianism" and Sasha Torres's "Television/Feminism: Heartbeat and Prime Time Lesbianism," both found in The Lesbian and Gay Studies Reader (ed. Abelove et al.). 
Ellen's executive producers]. "Almost all her friends are heterosexuals. If one of the other characters has a guy that they're interested in, she's the first to say, 'Omigod, he's hot'. It's just not going to be an option for Ellen to date him." (49)

This explicit rejection of lesbian desire (even dating is out of the question) and the positioning of Ellen squarely within the realm of heterosexuality ensure that deviance is isolated from the operations of the quotidian. Cut off from the lesbian community and apparently overjoyed to comment on the splendor of the opposite sex, DeGeneres's character is made to reinforce the supremacy of heterosexuality and the unnatural, marginal status of lesbianism. The rigorous assertion of normality initiates a split between sexual identity and sexual behavior (Ellen may be a lesbian, but she certainly must not act like one) and further serves to mark lesbian desire as deviant. Passing as normal enough within the visible realm requires that the a priori dichotomies of deviance and normality must clearly remain intact. The markers of normality ascribed to Ellen (Morgan and DeGeneres) bring her into the realm of primetime acceptability by playing her against stereotypical lesbianism, thereby insidiously reinforcing the deviant status of non-normative sexualities.

This reinforcement has been soundly critiqued by queer cultural theorists such as Judith Butler, Sally Munt, Peggy Phelan, and Eve Kosofsky Sedgwick for nearly a decade now. ${ }^{4}$ These critics, often drawing on the lessons of psychoanalysis, point toward the vast array of limitations that are always already embedded within the visible realm. Peggy Phelan provides (via Lacan) a concise accounting of these restrictions: "Visibility is a trap; it summons surveillance and the law; it provokes voyeurism, fetishism, the colonialist/imperialist appetite for possession. Yet it retains a certain political appeal" (6). Phelan foregrounds the apparent conundrum that visibility poses for activists and theorists alike. A simplistic

${ }^{4}$ See, for instance, Butler's Bodies That Matter, Munt's Heroic Desire: Lesbian Identity and Cultural Space, Phelan's Unmarked: The Politics of Performance, and Sedgwick's Tendencies. 
reliance on strategies of visibility opens a myriad of representational traps and inhibits the effectiveness of counterimages. And yet, in the face of numerous intense, articulate, and vigilant critiques of a visibility politic, I am left to wonder, along with Phelan, why its appeal still holds. Is there no other viable means through which a more diverse cultural imaginary may be fostered? Even the apparently disparate views held by various lesbian communities concerning the types of representational strategies that we should employ are surprisingly alike in their unwavering faith in the manipulability and controllability of the visible realm:

Some believe we should create only "positive images," which are most palatable to the mainstream. Some think we should represent the full spectrum of our lives - warts and all. Others contend that we should create an alternative lesbian culture that can stand completely outside the mainstream, while others assert that we should struggle to make inroads into mainstream film, music, and the like. (Stein 63-64)

None of these tactics pose any challenge to the system of representation itself, nor do they critically assess their own complicity within that system, whether as assimilationists or opponents. The question remains: if the costs of unproblematically taking up the visible are, as Phelan enumerates, truly significant, then what goal could possibly be worth the risk of inciting these traps?

I want to suggest that this seemingly high-risk scenario still retains its currency primarily because an over-reliance on visibility characterizes both a Western democratic tradition of "rights discourse" and, more importantly, the attendant notion of full and equal citizenship. The lesbian sex art of Vancouver-based performance collective Kiss \& Tell provocatively reimagines this nexus of visibility, rights, and citizenship. Kiss \& Tell's playful reconceptions of the relationship between citizenship and sexuality

${ }^{5}$ By 'rights discourse' I mean an appeal to a system of governance based on the legal protection of its subjects from discrimination through a state-approved set of protected identity criteria such as religious beliefs, ethnicity, race, sex, and so on. 


\section{$30 /$ Wray}

provide tantalizing examples of transformative cultural politics at work. Since the late 1980 s, Kiss \& Tell have dedicated their work to the goal of fostering a rich, and often contentious, lesbian imaginary. Kiss \& Tell confront conventional notions of citizenship to fashion a community whose boundaries are permeable and whose citizenry is uncertain. Before analyzing their projects in detail, I contextualize Kiss \& Tell's artistic interventions within debates concerning gay and lesbian rights, visibility politics, and community models.

Citizenship and 'rights discourse'exist in a reciprocal relationship to one another: to attain citizenship means that one has a specific claim to certain inalienable rights under national laws while, conversely, these rights are only conferred when one is marked as a citizen. A liberationist insistence on visibility is very much tied to an insatiable longing for one's rightful place within the national body, one's citizenship papers, and the only way in which that territory may be delineated is by marking and remarking one's claim to certain rights. As Alan Sinfield explains, the agency assumed by rights advocates is inherently problematic: "For it is not that existing categories of gay men and lesbians have come forward to claim their rights, but that we have become constituted as gay in terms of a discourse of ethnicity and rights" (271). A rights discourse works to the extent that it both constitutes and articulates the existence of an identifiable, marginalized group of people.

The multiple traps accompanying heightened visibility are intimately bound to the foundational paradox inherent in rights claims: one becomes a citizen equal to other citizens under national law at the moment one's position of 'otherness' is marked within the body politic. This conception of citizenship hinges upon the simultaneous declaration and display of difference and sameness. In other words, in order to be constituted as a group in need of rights protection and, therefore, entitled to full benefits under the law, the group must prove its disadvantaged or stigmatized status: that it is basically the same as any mainstream group, but not treated the same. Gays and lesbians cannot be naturalized as citizens until our relatively 'unnatural' status is reconfirmed.

Similarly, a liberationist appeal to rights legislation often overlooks the ways in which the power attached to a normative conception of citizenship is unwittingly reinforced by these rights 
claims. Borrowing from Judith Butler's arguments concerning the process of identity formation, it becomes tenable that the unmarked norms which regulate the very concept of citizenship (white, heterosexual, male, and so on) require the boundary-shoring actions of a constitutive outside in order to conceal their own nonoriginary, inauthentic status. Butler remarks: "This exclusionary matrix by which subjects are formed thus requires the simultaneous production of a domain of abject beings, those who are not yet "subjects," but who form the constitutive outside to the domain of the subject" $(1993,3)$. The "not yet" status of these subjects must be reiterated over and over again in order to stabilize and delineate the domain of subjectivity. At this point, Sinfield's insistence on the illusory nature of gay and lesbian agency within a rights discourse rings very true, indeed.

The late-twentieth-century employment of a rights discourse reiterates a normative citizen through a tacit reinforcement of the margin/center dichotomy that stresses the 'not yet' status of citizenship for homosexuals and, inadvertently, reproduces a domain of abject beings. More often than not, attempts to overcome this abject positioning involve, as I have suggested, the reassertion of normality through a distinct valorization both of mainstream gay and lesbian celebrities, as well as of the notion of nationhood itself. Writer Sarah Schulman astutely discerns this compulsion in her 1995 novel Rat Behemia. Troy Ruby, a central character in the text, reflects on the New York City chapter of Queer Nation:

Queer did get old very fast, nowadays only academics take it seriously. But Nation managed to live on in many fond conversations. Transgender Nation, Alien Nation, Reincar Nation. And all along the line no one noticed how much that word echoed with the secret store of nostalgic desire for normalcy, normalcy, normalcy. (111)

Even the so-called radical facets within liberationist organizing have frequently clung to the stability and privilege that discourses of national citizenship provide. Schulman makes her readers aware of the fact that organizations seeking a recognition of difference and diversity are unable and unwilling to critique the operations of national discourse, precisely because those operations hold the promise of sameness and equality for a community in need of 


\section{2 / Wray}

validation.

The "nostalgic desire for normalcy" bespeaks an investment in the psychic maintenance of traditional narratives of belonging and placement, and gestures toward the ways in which liberationist discourses of all kinds are haunted by the specter of their own outsider positioning. A rights discourse, seeking to produce a domain of intelligible and legitimate homosexual bodies, tends to replicate the mechanisms of exclusion by which the subject/citizen is formed. Again, in the words of Butler, "every oppositional discourse will produce its outside" $(1993,52)$. The result is a cyclical replaying of how normative categorizations are constructed, rather than the intended expansion of what full and equal citizenship might mean. Creating our own rules for citizenship - as emblematized in the call for distinct geographical locations, or in the uncritical engagement with a rights discourse - falsely ascribes liberatory power to outsider positioning. Although useful to visions of a lesbian utopia in which safety and community are secured through real or imaginary sites, the notion of "outsiderness" remains bound up with dominant discursive constructions of proper placement. The transformation of citizenship requires that we are highly cognizant of "the exclusions by which we proceed" (Butler 1993, 53). The politics espoused by a rights discourse are most frequently additive rather than transformative of the categories at hand.

The potential for transformation is not to be found within a full-scale abandonment or disavowal of the apparently overwhelming desire by gays, lesbians, and queers to secure a territory of their own within the national body politic. Indeed, as I have alluded to, the longing for full citizenship - and the stabilization of identity that it affords - is most often figured as an acute longing for place. In their introduction to the recent Queers in Space anthology, the editors remark upon the crucial role that spacemaking plays in minority communities: "Although in the late twentieth century space has become recognized as a signifier of a group's status in society, this realization has not yet transformed society or yielded real inclusion" (6). In a similar vein, Sally Munt observes that "the lesbian's movement through time and space is an act of her professed belief in an imagined community, one in which there is full citizenship for her" (173, my emphasis). This place may 
be conceptualized as an actual geographical location in which our own rules of citizenship apply (lesbian bars/clubs, lesbian ghettos, lesbian land, etc.), or place may be understood, more abstractly, as sites within the cultural, social, and political imaginary (lesbian films/books/plays/performances, lesbian politicians, lesbian mothers, etc.). Whether conceptualized as literal or abstract-or, more accurately, both-the allure of place-making and space-taking as a guarantor of citizenship is fundamental to the making of lesbian identity itself. In fact, as the quotation from Munt suggests, an almost seamless relationship between the quotidian and the imaginary defines the parameters of lesbian existence.

Much of this recent queer commentary on the interlining of the real and the imaginary in place-making, citizenship, and identity politics is indebted to Benedict Anderson's seminal text, Imagined Communities: Reflections on the Origin and Spread of Nationalism. Although Anderson does not address sexuality in any detail, his writing "furnishes a series of terms that have proven exceedingly useful for us" (Parker et al 5). Among those terms is, of course, the notion of the imaginary status of the nation. According to Anderson, the nation is imagined "because the members of even the smallest nation will never know most of their fellow-members, meet them, or even hear of them, yet in the minds of each lives the image of their communion" (15). Anderson's description powerfully resonates with Munt's aforementioned articulations of the "lesbian belief in an imagined community." As a queer culture we are not rooted in a particular geographical location, nor can we lay claim to territorial borders or other conventional markers of nation status. These conditions require that our paradigms of citizenship seriously account for the complicated and wonderfully playful operations of the imagination in queer community making. Similarly, the constraints that a heterocentric culture places on daily living can, in many ways, be countered only through a recourse to the imagination. ${ }^{6}$ Anderson's musings on the foundational role of the imagination in the constitution of all nations provides an obvious

${ }^{6}$ In the words of Sally Munt, "The imagination is of paramount importance in a heterosexual world which effaces our experience, by rendering us absent" (174). 


\section{4 / Wray}

theoretical framework for queer speculations on community and citizenship.

Our models of belonging (national or otherwise) must, however, foreground more than the use-value of the imagination as an identity-constituting force. In addition, an attentiveness to the inseparable nature of the actual and the imagined will be necessary in order to highlight both the historically-grounded power of discourse to materialize identities and the bodies attached to those identities, as well as the influence wielded over social and political realms by a cultural imaginary. In his recent essay "Queer Space," Jean-Ulrick Desert insists that "Queer space is in large part the function of wishful thinking or desires that become solidified" (21). Desert's description of queer space resists the impulse to stabilize boundaries or to concretize the abstractness attached to such a definition. In this way, a much more fluid, provisional, and nuanced version of space and, by extension, the citizens producing and produced by that space are made possible. Anderson's notion of the very real, yet very precarious, foundation of the nation, coupled with current examinations of the tenuousness of queer space, may serve as a rich paradigm for restrategizing the ways in which lesbian citizenship is pursued. Instead of relying on the inherently unreliable structures of visibility politics and rights discourses to make the lesbian subject culturally intelligible, a conception of citizenship that locates its existence somewhere in the interstice of reality and imagination can engender a more critical engagement with some of the foundational binaries of sexual identity: center/margin; homosexual/ heterosexual; and normal/deviant.

By way of illustration, I now turn to the artistic projects of lesbian performance collective Kiss \& Tell. They locate their roots in a 1984 megameeting of Vancouver feminists on the topic of sexual representation. From this meeting, a much smaller group of artists came together on a regular basis to make art that explored female and lesbian sexuality. Eventually, the group evolved into the current collective of Persimmon Blackbridge, Lizard Jones, and Susan Stewart. Their productions include Drawing the Line (1988), a photographic exhibit with an accompanying video and postcard book, numerous performance pieces such as True Inversions (1992) and the forthcoming That Long Distance Feeling, and a genre- 
crossing book, Her Tongue on My Theory (1994), filled with images, theoretical essays, and fictional fantasies. Each of these texts initiates a sexy invasion of both heteronormative and lesbiancentered cultural imaginaries that takes to task the "nostalgic desire for normalcy."

Kiss \& Tell most often refigure this normative desire through tactics of "aggressive re-territorialization" (Butler 1993, 86). They inhabit literal representational spaces (galleries, art institutions, books, videos) in order to inhibit the ways in which these sites contribute to the normative reiteration of identities within psychic/imaginary spaces. In other words, Kiss \& Tell put into artistic practice the aforementioned theoretical speculations on the intimate relationship between imagined and actual spaces and their involvement in the production of identities. Through intimate explorations of diverse bodies, sexualities, and sex, their images and performance pieces open representational spaces for lesbian desire within traditional artistic venues. Even more importantly, Kiss \& Tell question the configuration of that desire through self-reflective, parodic expositions of the ways in which a lesbian imaginary remains bound by normative representations. Their exhibits challenge conventional notions of citizenship (lesbian and otherwise) to suggest a community whose territory is unstable and whose membership is never certain. And yet, it is these seemingly disempowering qualities that enable the production of vibrant, erotic, passionate, questioning, and complicated citizens in Kiss \& Tell's work.

Kiss \& Tell embarked upon their reimagination of the relationship between normative cultural imaginaries and citizenship models with Drawing the Line, an exhibition of 100 photographs by Susan Stewart of lesbian sex acts between Persimmon Blackbridge and Lizard Jones. It has traveled the globe from Canada to Australia and has been shown sixteen times in fifteen cities since 1988. The images in Drawing the Line are hung on white walls, with a copious amount of white space left surrounding each photograph to be filled in with writing/graffiti (Figure 1: the exhibit on tour). They are also arranged from the least controversial (kissing, cuddling) to the more explicit (cunnilingus) and the most challenging (fisting, sadomasochism, male voyeurism, bondage). Drawing the Line is not 


\section{$36 /$ Wray}

an accounting of the facts, nor an homage to the diversity of the lesbian nation. Nor are Kiss \& Tell interested in testifying to the authenticity of the images, or to the 'realness' of the sexual acts they portray. Rather, they take up the crucial political task of revealing how "lesbian" has come to signify a sexual citizen within a heteronormative matrix of representation. As Judith Roof comments, "Politically and critically, understanding these configurations [of lesbian sexuality] may help us identify the oppressive sources of ideology that tend to delimit the cultural possibilities of individuals" (6). Drawing the Line does the deconstructive work of making viewers (lesbian or not) aware of their own delimiting actions. We are compelled literally to draw on the wall our lines of acceptance or rejection of particular images. Through these actions, Kiss \& Tell hopes that lesbians may become attuned to their own psychic processes of expulsion. The images lesbians deem unacceptable become the abject others who are exiled in order to remark a culturally imbued sense of what stable, normative citizenship entails.

Drowing the Line, in its spatial configuration of photographs, asks viewers to confront our often unacknowledged complicity with dominant, and highly exclusive, registers of acceptability. The white wall space found at the edges of these photographs provides room to scribble and thereby reveal and/or deface regulated cultural perceptions. The apparent emptiness and innocence of the white walls offers a seemingly liberating space in which to articulate one's views. Yet, as my earlier argument concerning the limitations of visibility politics outlines, an attentiveness to the cultural and social scripts that regulate representations and our reactions to them, even in these apparently "free" spaces, is crucial. The liberation associated with "positive images" becomes an untenable aspiration when we unravel the normalization processes embedded within mainstream systems of representation. As the case of Ellen DeGeneres illustrates, though, positive images are always already limited by the visual economy in which they appear and, more often than not, unwittingly reinforce a normal/deviant dichotomy. So too, the scrawls on the wall repudiate or validate the images at hand in accordance with dominant ideals concerning sex and sexuality. The writing in the white spaces of Drawing the Line actualizes the process of 
constructing 'acceptable' representations. Kiss \& Tell's exhibition, in its very structure, encourages viewers to reflect upon their own investments in normality and the extent to which these investments encroach upon all sexual representations. At the same time, the photographs themselves are shown to be embedded within the narratives lurking on the white walls.

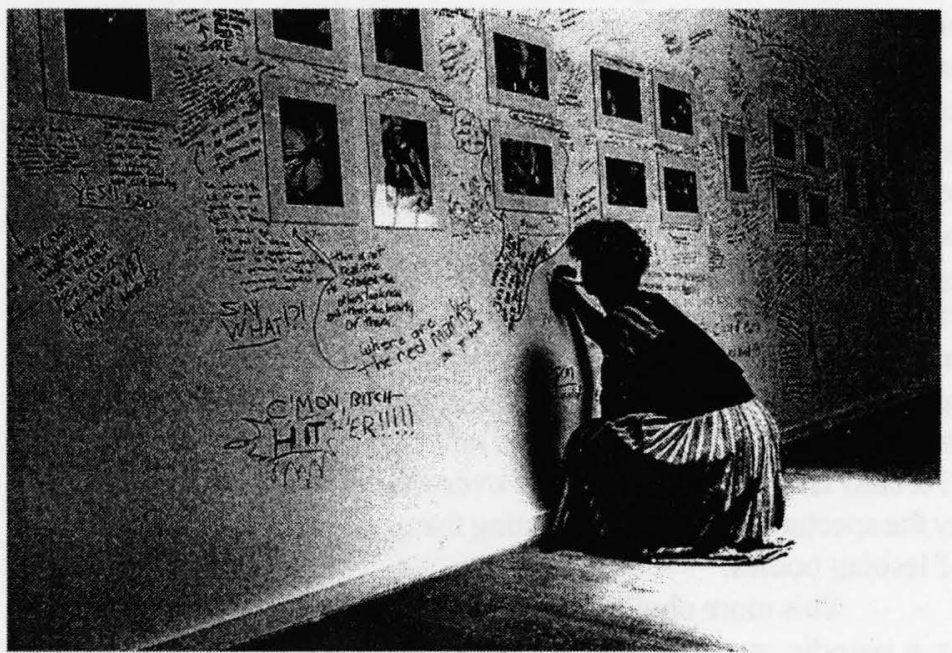

Figure 1: The exhibit on tour

C Kiss \& Tell, Isa Massu 1991

Significantly, only women were permitted to write on the walls, while men were encouraged to place their observations in the conventional form of a book left for visitors' comments. With this gesture, Kiss \& Tell laid bare another aspect of the traditional operations of dominant culture in which art concerning women, especially lesbians, is subject to a critical exoticization based upon patriarchal principles of critique. Such opinions in the exclusive interests of men are now destandardized in the concession of the visitors' book, an object usually shelved away or entirely discarded after an exhibit. But far from simply endorsing the lesbian-feminist adage of 'art by, for and about women', Drawing the Line ultimately succeeds in revealing to what extent such a utopian stance is illusory. The responses written on the gallery walls foreground the 


\section{8 / Wray}

ways in which a lesbian sexual imaginary remains intimately tied to normative discourses of sexual identity.

One manifestation of this connection may be seen in viewer responses to the shot of two women passionately kissing, framed by trees, rocks, and a waterfall (Figure 2). Echoing conventional depictions of (hetero)sexual love and commitment-wedding photos, for example, are frequently taken in gardens or parks - this photograph uses the geography of sexual acceptance to authenticate and naturalize desire between the two women. Lizard Jones knowingly comments on the impulse to recuperate sexual expression from its inherently 'dirty' status: "sex has to be redeemed by something. When it's done with the appropriately redeeming love, politics, or artistic merit, then sex becomes beautiful and important again, things it apparently can't be on its own" (Kiss \& Tell 1994, 48). Certainly, the natural beauty depicted in the photograph envelopes lesbian sex within a clichéd narrative of romanticized splendor. That one member of the audience at any rate finds this image comforting-"I love sex and nature. Too bad I have allergies" (Toronto show) - testifies to the overwhelming power still wielded by the specters of deviance haunting the representational appearance of lesbian bodies.

This more obvious reading of what could have been viewed as a parodic queering of the natural landscape, especially in the playful context of the entire exhibit, indicates the extent to which lesbian sex in public spaces remains bound by discourses of normality. In this reading, the beauty of the landscape fuses with public lesbian sex to ensure that illicit desire is recuperated as part of the natural order. ${ }^{7}$ The titillation offered by the dangers of kissing in public provokes one viewer to comment tentatively, "Feels dangerous - kissing outside - but maybe that's sexy too" (1991). The hesitation expressed in these sentiments again points toward the inescapable logic of dominant public/private discourses of space. It becomes clear that lesbian identity and desire are securely fastened

${ }^{7}$ The fusion of lesbian sex with natural landscapes commonly appears in lesbian-feminist photography as a means of highlighting the natural beauty of women's desire/anatomy. See, especially, Tee A. Corinne's images of female genitalia transposed onto seascapes and forests. 
to a notion of private and proper placement within national landscapes.

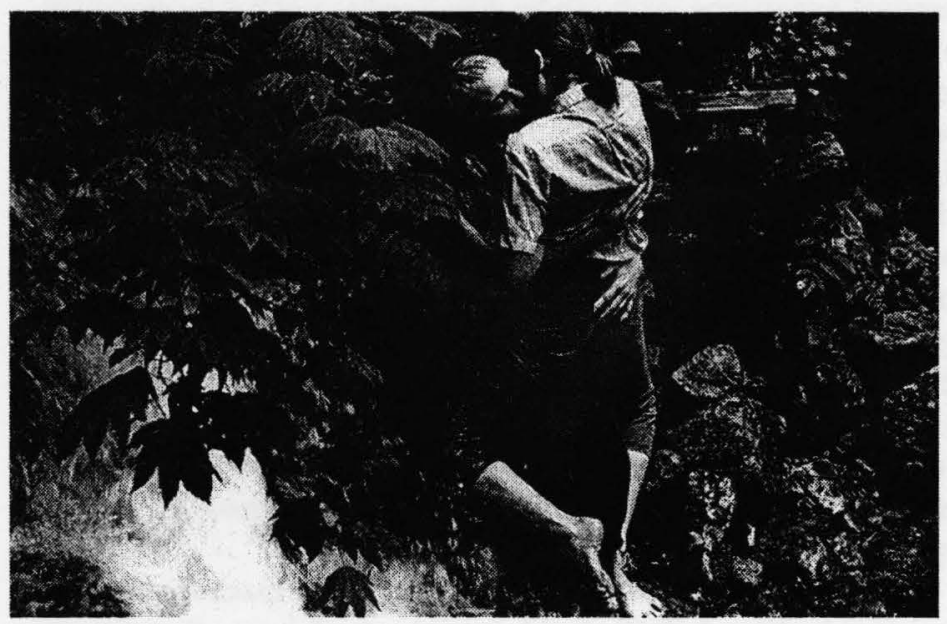

Figure 2: "I love sex and nature..."

C Kiss \& Tell 1991

Regardless of whether viewers find in the exhibit a convincing portrait of True Lesbian Love ${ }^{8}$ or, after reading the artists' statement, are appalled by the fakery of it all, these photographs, embedded within viewer commentary, succeed in creating a deeper understanding of the arbitrariness of such viewing practices. The comments are frequently contradictory and hint at the ability of the lesbian imaginary to sustain radically diverse readings. One viewer comments on one photo: "This touches me the most intensely because it looks like my experience of real live lesbian sex" (San Francisco show). And yet the same photo elicits quite another response from another viewer: "Looks like straight women in porn movies" (1991; San Francisco show). Which reading more accurately interprets the image at hand is not the point. These

${ }^{8}$ In her review of Drawing the Line and, more particularly, of the viewers' comments on the walls, Mary Louise Adams astutely remarks, "Women seemed to be searching for an elusive, essential, unencumbered lesbian sexuality. Love, it seems, is high on the natural, while props, jewelry, and even clothes are not" (43). 
responses demonstrate the limited scope of lesbian sexual representation; either the image can be discussed as mimetic of personal experience, or it can be dismissed as politically complicit. Such reactions are emblematic of the complex dialogue "drawing the line" initiates. In this instance, the line is meant to separate lesbian from straight, but the line does not hold. The project of differentiating 'real' lesbian sex from straight fakery is revealed as a fraught and ultimately futile endeavor because the line between the two is simultaneously a marker of difference and a site of commonality. In other words, the line must be drawn over and over again in order to reinforce a stable, bounded sense of sexual identity. Identification remains dependent upon that which it excludes, and this unending process exposes the fallacy of drawing the line. ${ }^{9}$ Cognizant of the paradoxes attached to drawing the line, a refigured lesbian imaginary highlights the inside/outside status of lesbian representation.

The ideological properties of the gallery space are similarly exploited by Kiss \& Tell's inside/outside playfulness. Drawing the Line turns the often government-funded public space of the traditional gallery into a truly interactive site: "Those polite and pristine gallery walls are soon scrawled over with writing. The photos float in a sea of text; not 'fine art objects' but part of a loud, rowdy community argument and celebration" (Kiss \& Tell 1994, 17). In this way, Kiss \& Tell fashion a precarious queer space that noisily invades gallery norms. Lesbian images, however briefly, stimulate a "loud, rowdy community" and point toward the artistic activism Kiss \& Tell engender.

Drawing the Line does not propose an alternative or oppositional imaginary but, instead, invades already existing narratives to expose their assumptions and limitations. This clears a space for a lesbian-specific discourse which is, in turn, exposed as

${ }^{9}$ Judith Butler explains the process of identity differentiation as ultimately untenable: "The line is supposed to differentiate straight from lesbian, but the line is contaminated by precisely that which it seeks to ward off: it bounds identity through the very same gesture by which it differentiates itself; the gesture by which it differentiates itself becomes the border through which contamination travels, undermining differentiation itself" $(1998,228)$. 
another constructed narrative replete with its own assumptions and limitations. The writing on the walls does not tell the story of a community hopelessly morally divided. Rather, it narrates the adventures of a citizenry actively engaged with its own representational dilemmas.

Kiss \& Tell's preoccupation with representation and the influence that this wields on citizenship paradigms continues to take center stage in their recent performance art. In November, 1992, Kiss \& Tell brought their performance piece True Inversions to the Banff Centre for the Arts, a publicly funded, internationally recognized arts institute located in the Canadian Rockies resort town. Their performance included a sexually graphic 30 -minute video, filmed and directed by Lorna Boschman, in which members of the collective act out sexual fantasies. The video begins with a close-up of cunnilingus. Almost immediately, this tantalizing image is covered over by an official-looking "censored" stamp citing Canada's Criminal Code. Throughout True Inversions, viewing pleasure is disrupted by such intrusive regulatory markers. Kiss \& Tell strategically display the emblem of Canadian censorship before national laws enact it for them and, in the process, explore the ways in which dominant representational rules tend to permeate even lesbian-centered sex art.

The infiltration of censorship regulations in the video is both a commentary on the federal regulation of lesbian images and, more complexly, also a gesture toward the constitutive power of normative representations within lesbian fantasies. The censorship marker makes visible the usually tacit operations of a heteronormative cultural imaginary. The pauses, the stamp of censorship across the screen, and the appearance of the Canadian Criminal Code legislation all underscore the tenuous relationship between sexuality and visibility; the moment that lesbians are marked within the field of vision is simultaneously the moment that they are displaced as equal citizens. The tactics of representation, which Kiss \& Tell employ in True Inversions, shift the lesbian imaginary out of its traditionally oppositional positioning and, instead, examine how it is possible to create lesbian art by making use of institutional constraints.

Kiss \& Tell's video deliberately calls attention to its own 


\section{2 / Wray}

production and apparatus - boom mikes, cameras angling for shots, the crew - in an effort to undermine the longing for simplistic realness often expressed by lesbian audiences like those noted above. Susan Stewart explains that, "the means of production carry their own weight of ideological baggage that must be both identified and subverted. That is why we like to show our crew, our untidy closets, our complicated histories" $(1994,112)$. If the viewer is not savvy enough to pick up on this resistance to realism, the director Boschman ensures that there will be no misrecognition of the realness of this video sex when she asks, "Is it real sex if you have to stop and start when the director tells you to?" And yet it looks real enough with real cunts and real lips and real asses sweating and moving together. The intrusiveness of the director, along with the use of gauzy curtains to obscure some of the images, blurs the line between representation and real sex, just as it undoes private/public dichotomies through its commentary on censorship.

Kiss \& Tell's Banff performance and, in particular, the video element of the production, ignited a flurry of controversy in the politically conservative province of Alberta. Right-wing magazines, local newspapers, and provincial radio talk shows had a field day with this lurid material. Headlines appeared across the Prairies with such delightful phrasing as "Tax-Funded Gay Sex Play "God-awful"” (Edmonton Sun 24), "Tax Dollars Funding Smut" (Avram, West-Central Crossroads 2), and "Even Lesbianism is Government Funded" (Avram, The Watson Witness 4). As if that vehemence were not enough, Ken Kowalski, the Deputy Premier of the Province, never having seen the show, called a press conference to denounce "this abhorrent lesbian show" (Edmonton Sun 24) and to ask his fellow cabinet members to help him put an end to homosexual shows at government-funded institutions. This was followed by many months of governmental wrangling over whether or not a standard of decency should be implemented as a prerequisite for obtaining arts funding in Alberta.

This rather reactionary, yet all too common, sequence of events began with the appearance of an article in the Alberta Report, an extreme right-wing weekly magazine. Reporter Rick Bell attended Kiss \& Tell's Banff show and subsequently wrote an inflammatory review entitled "Kissing and Telling in Balmy Banff." 
Since only about 150 people were actually present at the Banff performance, Bell's article formed the basis of the majority of both oppositional and supportive commentaries on their production. At the heart of these debates is a territorial battle over public space. The force of Bell's argument centers on his unrelenting discussion of the Banff Centre as a publicly-funded institution: "As usual, the money for this free-admission spectacle came from the empty coffers of indebted governments" (33). Ostensibly, Bell's invocation of "empty coffers" anchors his inflammatory rhetoric to a discourse of sound financial management. More accurately, Bell's comments belie his own investment in the distribution of Alberta's wealth. Bell's discussion of the state of the provincial treasury is a facade that covers over the more urgent issue of Kiss \& Tell's (for Bell) unacceptable traversal of public space with private acts.

It is no accident that critiques of Kiss \& Tell's performance figured along the lines of keeping lesbianism out of official public places. This reaction demonstrates not only the extent to which public spaces are tacitly designated as heterosexual or, in the words of Lauren Berlant and Elizabeth Freeman, "the boundedness of heterosexual spaces is also contingent upon the (enforced) willingness of gays to remain invisible" (162). The frenzied denunciation of Kiss \& Tell's show, particularly in the Alberta Report article, also exposes how the maintenance of these places as markers of 'decency' and cultural acceptability hinges upon the continual expulsion of the abject. According to Munt, "Spaces are not only gendered, and sexed, they are also moralized. Spatial boundaries are moral boundaries which expel the abject, due to the perception of difference as defilement" (166). The expulsion of the abject, as psychoanalytic discourse suggests, is a foundational and ongoing activity in the constitution of subjectivity. Hence, it is possible to read territorial battles, and conflicts over who has the right to representational space, for the ways in which they reveal the precariousness of identity categories. Often, the preoccupation with winning these spatial wars does not allow for an arms-length assessment of the rhetoric surrounding such debates, but such an analysis is crucial to the deconstruction of public/private dichotomies and the 'proper' placement of subjects that these binaries engender. Apparently unnerved by the fact that "the audience loved it 
all, bestowing overwhelming applause at the end and two curtain calls" (33), Bell redeploys a heterocentric narrative of the event that constructs it as the purview of 'special interest' groups. To this end, he describes the audience as "leather-clad art aficionados with spiky short haircuts searching for the ultimate meaning of lesbian sex" and "mainly female of the military crewcut variety. Black leather jacket, black miniskirt, black tights or black fishnet stockings, and black army boots or runners in orange or green were the prevalent fashion statement"' (33). Constructing the crowd as this supposedly otherthan-normal way for women designates this event as a deviant lesbian happening, enabling Bell to reinforce inhibiting notions of normative heterosexual femininity. In his ruminations on clothing, Bell neatly manages to heighten lesbian perversion by linking it to images of illicit sexuality (leather, miniskirts, and stockings) and rebellion (commando haircuts and army boots). Clearly, for Bell, a 'proper' woman was not to be found among this audience.

The anxiety surrounding Kiss \& Tell's Banff production speaks very loudly on the topic of heterosexuality. In the words of Butler, "It is crucial to remember that heterosexuality is itself beset by its own constitutive homosexual anxieties; it is not as separate or separable from the sexual minorities from which it tenaciously tries to distance itself' $(1998,227)$. The Banff controversy reveals exactly how tenuous the category of normal really is, and how dependent it is upon its excluded 'others'. As a political act, Kiss \& Tell's performance lays bare the spatial operations of a heterocentric cultural imaginary and in so doing opens the possibility of a more self-reflexive occupation of location. Kiss \& Tell's performance, then, traverses both literal and imaginary sites of identity production to expose the interlocking nature of these territories. It is precisely their refusal to inhabit properly this nexus of identification that initiates the critical process of reconfiguring citizenship paradigms, be they national or sexual.

A politics of dissent, even disidentification, permeates the work of Kiss \& Tell. These lesbian sex artists are less interested in resolving representational dilemmas than in returning contentious issues to their viewers. As Susan Stewart explains: "One of Kiss \& Tell's strategies has been to begin making images, despite the contradictions. Images that start to articulate a kind of lesbian 
imaginary, even when it seems an act of pure invention" (Kiss \& Tell 1994, 112). Of course, this is not a simple process. It may be, as Stewart continues, "inconclusive and unresolved" with "more questions than answers" but, crucially, it is "a place to work." A place located amidst the censors and the ghosts of lesbian representation, but a place, nonetheless.

\section{Works Cited}

Adams, Mary Louise. "Review: Drawing the Line." Fuse 14 (1990): 42-44.

Anderson, Benedict. Imagined Communities: Reflections on the Origin and Spread of Nationalism. London: Verso, 1983.

Avram, Kevin. "Even Lesbianism is Government Funded." The Watson Witness (Canora, Sask.) 6 Jan. 1993: 4.

—. "Tax Dollars Funding Smut." West-Central Crossroads (Kindersley, Sask.) 6 Jan. 1993: 3.

Bell, Rick. "Kiss \& Telling in Balmy Banff." Alberta Report 7 Dec. 1993: 33.

Berlant, Lauren and Elizabeth Freeman. "Queer Nationality." boundary 219 (1992): 149-80.

Butler, Judith. Bodies That Matter. New York: Routledge, 1993.

_. "Afterword." Butch/Femme: Inside Lesbian Gender. Ed. Sally Munt. London: Cassell, 1998. 225-30.

Clark, Danae. "Commodity Lesbianism." The Lesbian and Gay Studies Reader. Ed. Henry Abelove et al. New York: Routledge, 1993. 186-201.

Corinne, Tee A. "Redwood Isis." Nothing But The Girl: The Blatant Lesbian Image. Ed. Susie Bright and Jill Posener. New York: Freedom, 1996. 108.

Desert, Jean-Ulrick. "Queer Space." Queers In Space. Ed. Gordon Brent Ingram et al. Seattle: Bay, 1997. 17-26.

Edmonton Sun. "Tax-Funded Gay Sex Play 'God-awful'." 15 Jan. 1993: 24.

Ingram, Gordon Brent, Anne-Marie Bouthillette, and Yolanda Retter. "Lost in Space: Queer Theory and Community Activism at the Fin-de-Millenaire." Queers in Space. Ed. 
$46 /$ Wray

Gordon Brent Ingram et al. Seattle: Bay, 1997. 3-15.

Kiss \& Tell. Drawing the Line: Lesbian Sexual Politics on the Wall. Vancouver: Press Gang, 1991.

- True Inversions. Dir. Lorna Boschman. Vancouver: Video Out, 1992.

- Her Tongue on My Theory: Images, Essays and Fantasies. Vancouver: Press Gang, 1994.

Munt, Sally. Heroic Desire: Lesbian Identity and Cultural Space.

New York: New York University Press, 1998.

Parker, Andrew, Mary Russo, Doris Sommer, and Patricia Yaeger.

"Introduction." Nationalisms and Sexualities. Ed. Andrew

Parker et al. New York: Routledge, 1992. 1-18.

Phelan, Peggy. Unmarked: The Politics of Performance. New York:

Routledge, 1993.

Roof, Judith. A Lure of Knowledge: Lesbian Sexuality and Theory.

New York: Columbia University Press, 1991.

Schulman, Sarah. Rat Bohemia. New York: Dutton, 1995.

Sedgwick, Eve Kosofsky. Tendencies. Durham, NC: Duke University Press, 1993.

Sinfield, Alan. "Diaspora and Hybridity: Queer Identities and the Ethnicity Model." Textual Practice 10.2 (1996): 271-93.

Stein, Arlene, ed. Sisters, Sexperts, Queers: Beyond the Lesbian Nation. New York: Plume, 1993.

Torres, Sasha. "Television/Feminism: Heartbeat and Prime Time Lesbianism." The Lesbian and Gay Studies Reader. Ed. Henry Abelove et al. New York: Routledge, 1993. 176-85. 